\title{
Activity of Some Enzymes in Developing Muscle of the Pig
}

\author{
C. C. Cooper, R. G. Cassens ${ }^{[33]}$, L. L. Kastenschmidt, and E. J. Briskey \\ Muscle Biology Laboratory, University of Wisconsin, Madison, Wisconsin, USA
}

\begin{abstract}
Extract
Total phosphorylase, lactic dehydrogenase (LDH), and glutamate-oxaloacetate transaminase (GOT) activities and lactic dehydrogenase isozyme patterns were determined on longissimus (white) and trapezius (red) muscles of developing pigs between the ages of 1 day and approximately 24 weeks. All enzyme activities were similar in both muscles at day 1 . Phosphorylase and LDH activities in longissimus muscle increased rapidly and by 24 weeks there was a 4 - and 10-fold increase in activities for the two enzymes, respectively. The GOT activity also increased but not to the same extent. Phosphorylase, LDH, and GOT activities of the trapezius muscle increased about 2-fold as the animal matured. Phosphorylase and GOT activities peaked in both muscles and then declined to adult values whereas LDH increased to the adult level. The $\mathrm{LDH}$ isozymes I and II were the major isozymes and $\mathrm{V}$ was a minor isozyme in both muscles at day 1 of age. In the adult, $\mathrm{V}$ was the major isozyme in longissimus muscle and $\mathrm{I}$ and $\mathrm{V}$ were the major isozymes in trapezius muscle.
\end{abstract}

\section{Speculation}

The muscle of developing pig undergoes biochemical changes associated with fiber type differentiation. The muscle, however, displays a unique grouping of fiber types, and we believe that this unusual morphology, occurring as it does in a normal biochemical environment offers a favorable experimental model for study of the basis of differentiation.

\section{Introduction}

The development of muscle involves cliange. DennyBrown [12] showed that skeletal muscle tended to be of the slow type at birth with differentiation into both fast and slow types soon after birth.

Many histochemical studies $[2,4,10,15,28]$ have demonstrated the differentiation of fiber types. The muscle of man and of guinea pig is fully differentiated at birth, but differentiation occurs postnatally in the muscle of such animals as mouse, rat, and rabbit [14].

Both the functional aspects and histochemical re- sults are an expression of the biochemistry of the muscle fiber. In predominantly red muscle of rhesus monkeys, Beatty et al. [3] found that $\mathrm{QO}_{2}$ and $\mathrm{CO}_{2}$ production were higher, similar, and lower at 90,125 , and 155 days gestational age, respectively, than observed in red muscle of adult animals. The glucose uptake of fetal muscle at 90 and 125 days gestational age was higher than that of adult muscle. Bocek $e t$ al. [6] did not find a consistent correlation between glycogen content and glycogen synthetase or phosphorylase activities in fetal, neonatal, and adult rhesus monkeys. Latzkovits and Domonkos [19] found that the metabolism of rab- 
bit skeletal muscle changed from that characteristic of tonic to tetanic during postmatal differentiation. Kendrick-Jones and Perry [18] related the rise in adenosine monophosphate deaminase activity of rabbit leg muscle with increased activity of the muscle as the animal began to move about.

The control of differentiation in developing muscle is not understood, but histochemical studies [7,9] suggest that developing muscle of the pig is favorable for experimentation on this problem. A unique clumped distribution of red fibers, not found in other mammalian species, is established by the time differentiation is detectable.

The objective of the present research was to study the biochemistry of developing pig muscle to establish if changes occurred that were similar to those found in other mammalian species. Total phosphorylase and total LDH activities were measured as indicators of anaerobic metabolism, and glutamate-oxaloacetate transaminase (GOT) activity was measured as an index of aerobic metabolism. The GOT activity was used as an oxidative indicator because of its constant proportion relation with other enzymes of the citric acil cycle [26]; LDH isozyme patterns also were studied.

\section{Materials and Methods}

\section{Animals}

Female Poland China (PP), Yorkshire (YY), Poland China $\times$ Yorkshire $(\mathrm{PY})$, and Yorkshire $\times$ Poland China (YP) pigs were used in this study. Two animals from each of the four classes were randomly selected for study at day 1 and at $1,3,5$, and 8 weeks of age. Three YY and three PP were studied at $90 \mathrm{~kg}$ live body weight (about 24 weeks of age) to serve as adult controls.

\section{Sample Preparation}

Samples of the longissimus (white) and trapezius (red) muscles $(500 \mathrm{mg})$ were removed immediately after the animal was killed and homogenized for $15 \mathrm{sec}$ in $20 \mathrm{ml}$ buffer (20 mM mercaptoethanol, $20 \mathrm{~mm} \beta$-glycerophosphate); the buffer was adjusted to $\mathrm{pH} 6.0$ to minimize the action of the phosphoglucomutase system [27]. The homogenate was centrifuged at $3,000 \times g$ for $15 \mathrm{~min}$, and the supernatant was used for analysis.

\section{Phosphorylase Activity}

The phosphorylase (alpha-glucan phosphorylase, EC. $2.4 .1 .1)$ reaction was measured in the direction, gly- cogen + glucose l-P $\rightarrow$ glycogen $+P_{1}$, by monitoring inorganic phosphate release [17]. The concentrations of the reactants at $\mathrm{pH} 6.0$ were: glucose 1-phosphate, $37.5 \mathrm{~mm}$; glycogen, $1 \%$; adenosine 5 '-phosphate, $1 \mathrm{~mm}$; $\beta$-mercaptoethanol, $10 \mathrm{~ms}$; and $\beta$-glycerophosphate, $10 \mathrm{~mm}$. The temperature was $30^{\circ}$. The aliquots of the reaction mixture were withdrawn at 5 -min intervals during the 15-min incubation period. Under the conditions employed, the release of inorganic phosphate was linear with time. Inorganic phosphate was measured by the method of Fiske and SubbaRow [16].

\section{Lactic Dehydrogenase Activity}

The lactic dehydrogenase activity (EC.1.1.2.3.) was measured in the direction L-lactate $+\mathrm{NAD} \rightarrow \mathrm{NADH}$ $+\mathrm{H}^{+}+$pyruvate [25]. The concentrations of the reactants at pH 10 were: glycine, $90 \mathrm{~mm}$; sodium DL-lactate, $25 \mathrm{~mm}$; NAD, 1 mm. The reaction was monitored spectrophotometrically at $340 \mathrm{~m}_{\mu}$ using a recording spectrophotometer [29] adjusted for a full scale absorbancy of 0.1 . The reaction was started by adding 0.020 $\mathrm{ml}$ of suitably diluted muscle extract to $2.0 \mathrm{ml}$ of the reaction mixture. The initial linear portion of the curve was used to calculate activity.

\section{Glutamate-Oxaloacctate Transaminase Activity}

Glutamate-oxaloacetate transaminase (EC. 2.6.1.1.) activity was measured in the direction, aspartate $+\alpha$ ketoglutarate $\rightarrow$ oxaloacetate + glutamate, using a coupled assay system containing malic dehydrogenase, $\mathrm{NADH}$, aspartate, $\alpha$-ketoglutarate, and phosphate [5]. The concentrations of the reactants at $25^{\circ}$ were: aspartate, $191.7 \mathrm{~mm}$; malic dehydrogenase, 0.875 enzyme units; inorganic phosphate, $90 \mathrm{~ms} ; \alpha$-ketoglutarate, 6.7 mar. A 10-min preincubation period was allowed after the addition of $0.1 \mathrm{ml}$ sample to $2.8 \mathrm{ml}$ reaction mixture not containing $\alpha$-ketoglutarate. The reaction was started by addition of $0.1 \mathrm{ml} \alpha$-ketoglutarate solution. The temperature was held constant at $25^{\circ}$. The oxidation of NADH was followed with the spectrophotometer [29].

\section{Soluble Protein}

Protein determination of the sample extract employed the procedure of Lowry et al. [20]. The extract was diluted 1 to 5 with water to minimize the interference of mercaptol groups. The reaction mixture contained $1.83 \mathrm{~mm}$ sodium potassium tartrate, $1.34 \mathrm{mM}$ copper sulfate, 0.3 м sodium bicarbonate buffer, $36 \mu \mathrm{M}$ mercaptoethanol, and $36 \mu \mathrm{Mr} \beta$-glycerophosphate. The 
reaction was incubated $15 \mathrm{~min}$ at $45^{\circ}$ and cooled quickly in an ice bath. Phenol, 2 м [30], was added, and the color was developed for $30 \mathrm{~min}$ before reading at $660 \mathrm{~m} \mu$. Bovine serum albumin standards were used.

\section{Lactic Dehydrogenase Isozymes}

Lactic dehydrogenase isozymes were separated by polyacrylamide gel disc electrophoresis [13]. Ten microliters of extract were mixed with $40 \mu \mathrm{l} 40 \%$ sucrose. This mixture was layered carefully with a syringe at the top of the gel. The resultant gels were scanned in an integrating densitometer, and readouts were used to calculate the percentage of total lactic dehydrogenase for each isozyme.

\section{Results and Discussion}

Enzyme activities (Fig. 1) were similar in the trapezius and longissimus muscles at $l$ day of age. The activity of all three enzymes (phosphorylase, LDH, and GOT) increased significantly in both muscles during the first 3 weeks of life, but there was a more rapid increase in activity of those enzymes which characterize that muscle in the adult animal. Adult white muscle (longissimus) has a higher soluble protein content, greater activity of enzymes associated with glycolysis (phos-
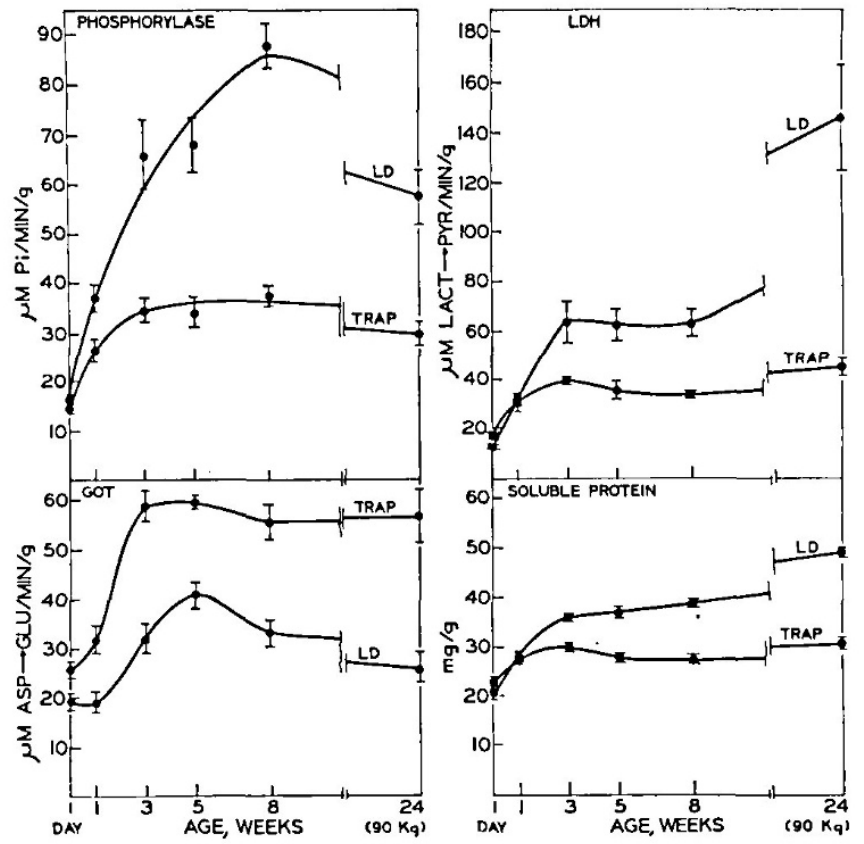

Fig. 1. Changes in enzyme activities and soluble protein concentrations during development. LD: Longissimus; trap: Trapezius. Results are expressed on a wet basis. Means are from six-eight animals, and the attached bar is the standard error of the mean.

\section{Longissimus}
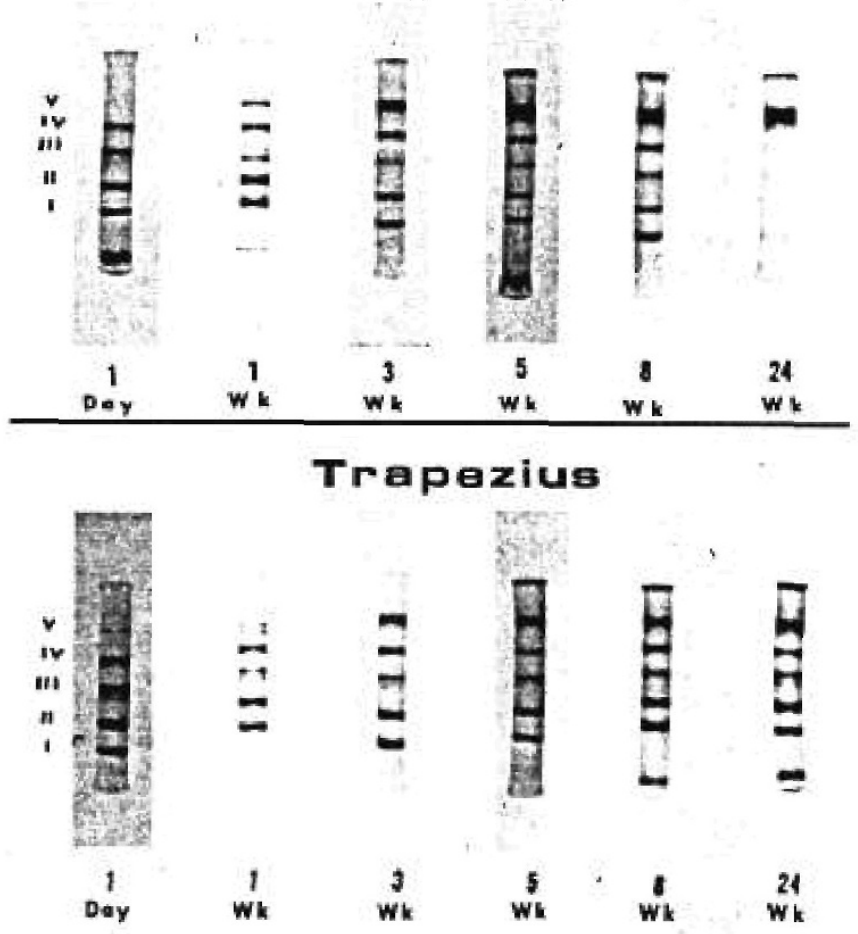

Fig. 2. Lactic dehydrogenase isozyme patterns. Isozyme bands are labelled as I, II, III, IV, and V. Representative gels are shown for both the longissimus and trapezius muscles at the indicated time periods.

phorylase, LDH), and a lower activity of enzymes associated with aerobic metabolism (GOT) than does red muscle (trapezius). Soluble protein content increased rapidly during the first 3 weeks and then approached the adult value at a slower rate. Likewise, major changes in LDH isozyme pattern (Figs. 2 and 3) occurred early but thereafter changed slowly to adult values.

Muscle usually accumulates fat as it develops, but expression of our results on a soluble protein basis resulted in patterns similar to those of Figure 1. The presence and effect of activators and inhibitors, on the enzymes studied, is unknown.

Statistical analysis showed no difference due to genetic breed, and therefore all breeds were pooled at each time interval and the results expressed as means from either eight or six animals.

\section{Longissimus Muscle Enzyme Activities}

There was an early rapid increase (Fig. I) in enzyme activities (phosphorylase, LDH) associated with anacr- 


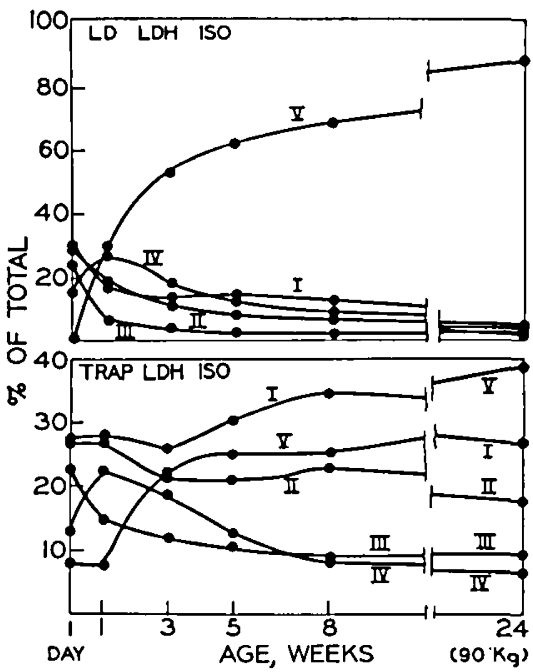

Fig. 3. Graphical representation of changing LDH isozyme pattern as a function of animal age. Results are expressed as a percentage of total peak areas. LD, LDH, ISO: Longissimus lactic dehydrogenase isozymes and trap LDH, ISO: Trapezius lactic de. hydrogenase.

obic metabolism in this white muscle. The LDH activity plateaued at 3 weeks and then increased thereafter to adult levels. Phosphorylase activity continued to increase through 8 weeks of age. Phosphorylase and $\mathrm{LDH}$ activities in the 24-week-old pig were approximately 4- and 10-fold higher, respectively, than the 1-day values. Activity of GOT increased approximately 2-fold to 5 weeks and declined gradually thereafter. This change was similar to the decrease in succinic dehydrogenase activity in chicken muscles reported by Cosmos and Butler [10]. Red fibers in pig muscle differentiate within the first week postpartum and are readily distinguishable histochemically as being low in phosphorylase activity and high in NADH-TR [9]. Typical white fibers can be identified clearly at 4 weeks. Even though red fibers are identified early in week 1 with histochemical methods, the GOT activity continues to increase through about week 5 . Conversely, the white fibers cannot be identified clearly with histochemical methods until about week 4 , but the phosphorylase activity increases markedly from day 1 onwards through about 8 weeks. This points out the difficulty of comparing histochemical with biochemical results.

The decline in phosphorylase and GOT activities (after a peak value) coincides with the decrease in physical activity of the pig from about that age to maturity. The continued increase in total LDH activity (Fig. 1) does not conform with this idea. An in- crease in net synthesis as well as a proportional change in LDH isozymes subunits (Figs. 2 and 3), however, must be considered. Dubowitz [14] supported the idea that stage of maturity at birth affects the histochemical differentiation, with the more mature animals already having fully differentiated muscle at birth. KendrickJones and Perry [18] suggested that the physical activity pattern of the muscle preclicts the time at which the enzyme activities of special significance for muscle rise sharply to adult values. Pigs are rather mature at birth as judged from their hair coat and are also active from the time of birth. The phosphorylase and GOT activities rise sharply from birth and then show a slowing or actual decrease in activity at about 8 weeks. This may be related to declining activity of the pig at this time as it is furnished with a complete food supply in moderate confinement.

Needham [24], Czok and Bücher [11], and Bárány et al. [1] have all shown soluble protein to be higher in white muscle than red muscle. Our results (Fig. 1) support these previous findings.

\section{Trapezius Muscle Enzyme Activities}

The trapezius muscle when observed in adults is a red muscle. It is, however, composed of nearly equal proportions of red and white fibers [22]; in contrast, the longissimus contains only about $15 \%$ red fibers on a total fiber area basis. Thus, it was not unexpected that the anaerobic (phosphorylase, LDH) and aerobic (GOT) enzyme activities of the trapezius (Fig. I) would both increase to the same extent (twofold) as the animal matures. All enzyme activities increased rapidly during the first 3 weeks and leveled off after reaching a peak. This correlates well with the early clear differentiation seen in the red fiber type compared with the appearance of the typical white fiber which exhibits a more gradual differentiation pattern [9]. Soluble protein (Fig. 1) content increased during the first 3 weeks of life and remained rather constant thereafter.

\section{Lactic Dehydrogenase Isozymes}

The changes in LDH isozyme pattern as muscle develops are illustrated as a gel photocomposite (Fig. 2) and as a graphical representation (Fig. 3) of densitometer tracings converted to a "percentage of total" basis. The isozyme pattern changed greatly during the first few weeks. In both muscles, at day 1 of age, isozymes I and II were the major isozymes and isozyme $\mathrm{V}$ was a minor component. In the longissimus, isozyme $\mathrm{V}$ rose 
rapidly and isozymes I, II, III, and IV decreased after week 1 . This rapid increase in isozyme $V$ fits well with the increase in total activity of LDH in longissimus muscle.

$\Lambda$ different distribution pattern developed in trapezius muscle. At day 1 of age there was a declining proportional distribution in isozyme content from isozyme I to $\mathrm{V}$. As the animal matured, isozyme $\mathrm{V}$ in. creased, whereas isozyme I remained rather constant. In the adult there was a linger percentage of isozymes $I$ and $V$ than there was of the hybrid isozymes II, III, and IV.

The relative abundance of the different isozymes corresponds with the metabolic requirements of the tissue [21]. Some aclult skeletal muscles, such as the longissimus, function under conditions of relatively low oxygen supply [8] and produce substantial quantities of lactate. Such tissues contain predominantly isozyme $V$ or hybrid isozymes high in muscle type subunits. Highly oxygenated tissues that produce little lactate, have a high content of isozyme 1 or hybrid isozymes high in heart type subunits. During periods of heightcned metabolic activity and increased glucose utilization larger amounts of pyruvate are produced, and this would normally lead to more lactate. Tissues relying on isozymes I or II would thus be prevented from converting the larger quantities of pyruvate to lactate because of the progressive increase in inhibition of those isozymes by pyruvate. Isozyme $\mathrm{V}$ exhibits higher catalytic activity in high pyruvate concentrations and thus those tissues rich in isozyme $V$ are able to convert large quantities of pyruvate to lactate [21]. In terms of oxygen supply to the tissues it is of interest to note that at vascular network resembling the adult counterpart, as well as myoglobin specificity to type I fibers, develops during the first few weeks of postnatal life in the pig [23].

\section{Summary}

Longissimus (white) muscle from adult pigs had a higher soluble protein content, greater activity of enzymes associated with glycolysis, and lower activity of enzymes associated with acrobic metabolism than did trapexius (red) muscle. Enzyme activities were similar in both muscles at day 1 of age. There was a marked increase in activity of all three enzymes (phosphorylase, LDH, GOT) during the first 3 weeks in both muscles. There was a more rapid increase in activity, however, of those enzymes that characterize that muscle in the adult animals. The LDII isozymes I and II were the major isozymes and $V$ was a minor isozyme in both muscles at day 1 of age. In the adult animal, isozyme $V$ was the major isozyme in longissimus muscle and isozymes $I$ and $V$ were the major isozymes in traperius muscle.

\section{References and Notes}

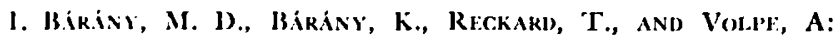
Myosin of fast and slow muscles of the rabbit. Arch Biochem. Biophys., 109: 185 (1965).

2. BenTY, C. H., Basingik, G. M., AND Bocek, R. M.: Differelltiation of red and white fibers in muscle from fetal, nconatal and infant rhesus monkeys. J. Histochem. Cytochem., 15: 93 (1967).

3. BeAtT, C. H., BAsiscek, G. M., MD BOCEK, R. M.: Oxygen consumption and glycolysis in fetal, nconatal, and infant muscle of the rhesus monkey. Pediatrics, 12: 5 (1968).

4. BF(Kk.1T, E. B., ANd BourNf, G. H.: Some histochemical observations on enzyme reactions in goat foetal cardiac and skeletal muscle and some human foctal muscle. Acta Anat., 35: 292.4 (1958).

5. BERGMEYF, H. U., AND BERNT, E.: In: H. V. Bergmeyer: Methods of Enzymatic Analysis (Academic Press, New York, $19(65)$.

6. Bock, R. M., Basivgek, G. M., AND BfatrY, C. H.: Glycogen symthetase, phospiorylase, and glycogen content of develop. ing rhesus muscle. P'ediat. Res., 3: 525 (1969).

7. Cassens, R. G., CoOper, C. C., MoOny, W. G., ANd Briskey, F. J.: Histochemical differentiation of fibre types in developing porcine muscle. J. Anim. Morphol. Physiol., 15: 135 (1968).

8. Coopre, C. C., Cassfas, R. G., and Briskey, E. J.: Capillary distribution and fiber chanacteristics in skeletal muscle of stress-susceptible animals. J. Food Sci., 3f: 299 (1969).

9. Cooper, C. C., Cassens, R. G., Kastenscimidt, L. L., and BrIski:, F. J.: Histochemical characterization of muscle differentiation. Develop. Biol., 23: 169) (1970).

10. Coswos, F., AND Burter, J.: Differentiation of fiber types in muscle of normal and dystrophic chickens. Excerpta Med. Int. Congr. Ser., 147: 197 (1967).

II. Cæok, R., ANd Bücm:r, T.: C.rystallized enzymes from the mycogen of rabbit skeletal muscle. Advan. Protein Chem., 15: 815 (1960).

12. DExwy-Bkows, 1). E.: The histological features of striped muscle in relation to its functional activity. Proc. Roy. Soc. I.ondon Ser. B., 104: 371 (1929).

13. Di:Tz, $\Lambda$. A., AND Lurkano, T.: Scparation and quantitation of lactic dehydrogenase isocnzymes by disc electrophoresis. Anal. Biochem., 20: 246 (1967).

14. Dunowitz, V.: Developing and Diseased Muscle. A Histochemical Study (Spastics International Medical Publications and William Heineman Medical Books, Ltd., City, 1968).

15. Fintcuft, G. M.: A histochemical study of developing hu. man skeletal muscle. Neurology, 16: 741 (1966).

16. Fisky, C. II., and Subiakow, Y.: The colorimetric determina(ion of phosphorus. J. Biol. Chem., 66: 375 (1925).

17. Hi:DRick, J. L., AND Fiscier, E. H.: On the role of pyridoxal 5 '-phosphate in phosphorylase. I. Absence of classical vitamin $\mathrm{B}_{\mathrm{g}}$-dependent enzymatic activities in muscle glycogen phosphorylase. Biochemistry, f: 1337 (1965). 
18. Kendrick-Jones, J., ANd Perry, S. V.: The enzymes of adeninc nucleotide metabolism in developing skeletal muscle. Biochem. J., 103: 207 (1967).

19. Latzkovits, L., AND Dononkos, J.: The effect of postnatal development on the carbohydrate metabolism of tonic and tetanic muscles. Acta Physiol. Hung., 28: 253 (1965).

20. Lowry, O. H., Rosebrough, N. J., Farr, A. L., ANd RANdall, R. J.: Protein measurement with the Folin phenol reagent. J. Biol. Chem., 193: 265 (1951).

21. MARKert, C. J., AND Ursprunc, H.: The ontogeny of isozyme patterns of lactate dehydrogenase in the mouse. Develop. Biol., 5: 363 (1962).

22. Moody, W. G., AND CAssens, R. G.: Histochemical differentiation of red and white muscle fibers. J. Anim. Sci., 27: 961 (1968).

23. Morita, S., Cooper, C. C., Cassens, R. G., Kastenscimidid, L. L., AND BRISKEY, E. J.: A histochemical study of myoglobin in developing muscle of the pig. J. Anim. Sci., 31: 664 (1970).

24. Needham, D. M.: Red and white muscle. Physiol. Rev., 6: 1 (1926).

25. Neilands, J. B.: In: S. P. Colowick, and N. O. Kaplan: Methods in Enzymology, Vol. 1 (Academic Press, New York, 1965).

26. Petre, D.: In: J. M. Tager, S. Papa, E. Quagliarullo, and E.
C. Slater: Regulation of Metabolic Processes in Mitchondria (Elsvier, Amsterdam, 1966).

27. Sutuerland, E. W.: The effect of the hyperglycemic factor and epinephrine on enzyme systems of liver and muscle. Ann. N. Y. Acad. Sci., 54: 693 (1952).

28. WirSEN, C., AND LARSSON, K. S.: Histochemical differentiation of skeletal muscle in foetal and newborn mice. J. Embryol. Exp. Morphol., 12: 759 (1964).

29. Model 2000, Gilford Instrument Labs, Obcrlin, $O$.

30. Fisher Scientific Company, Pittsburgh, Pa.

31. Published with the approval of the Director of the Wisconsin Agricultural Experiment Station, Department of Mcat and Animal Science Manuscript no, 567. Supported in part by Public Health Service Research Grant no. FD-00107-11 and by cooperative Department of Agriculture-CSRS Grant no. 816-15-20.

32. The authors report the unexpected death of their co-worker Dr. L. L. Kastenschmidt during the final preparation of this report.

33. Requests for reprints should be addressed to: R. G. Cassens, Ph.D., Muscle Biology Laboratory, University of Wisconsin, Madison, Wisc. 53706 (USA).

34. Accepted for publication Scptember 16, 1970. 